\title{
Choreo-athetosis with severe thyrotoxicosis
}

\author{
Peter Marks \\ M.B., Ch.B., M.R.C.P., M.Sc.
}

\author{
JOHN ANDERSON \\ B.Sc., M.A., M.D., F.R.C.P., F.I.Biol.
}

\author{
RICHARD VINCENT \\ B.Sc., L.R.C.P., M.R.C.P. \\ Department of Medicine, King's College Hospital Medical School, \\ Denmark Hill, London 8
}

\begin{abstract}
Summary
Two cases of severe thyrotoxicosis are described. They both exhibited choreo-athetoid movements which were abolished by successful treatment of the thyrotoxicosis. It is suggested that the tremor of mild thyrotoxicosis is one end of a spectrum at which choreo-athetosis is at the most severe end. A tentative explanation of this hypothesis is given in the discussion.
\end{abstract}

\section{Introduction}

Fasting plasma tyrosine is raised in hyperthyroidism (Hall, Anderson and Smart, 1969) and serum magnesium levels are low in severe thyrotoxicosis (Marks and Ashraf, 1978). Although tyrosine hydroxylase is the rate-limiting enzyme in the metabolism of tyrosine it is conceivable that more dihydroxyphenylalanine is formed under these conditions which may give rise to choreiform movements.

Two cases of chorea are described with responses and treatment. It is concluded that chorea is the severe end of the spectrum of dyskinesia of which tremor is the most common manifestation of milder thyrotoxicosis. It is also considered that chorea may be a commoner manifestation than previously described.

\section{Patient 1}

A 16-year-old girl presented with loss of appetite and loss of weight, about $12.7 \mathrm{~kg}$ in 3 months. She had some recent hair loss. Marked sweating was associated with irritability and poor concentration with poor sleeping at night. She had recently been having nocturia which was a new feature. Her past history revealed no serious illnesses. Her father had died 9 months previously from diabetic coma. There were no other family illnesses.

Physical examination revealed a thin girl. She was very restless but co-operative. Her pulse was $128 / \mathrm{min}$ and regular.

Heart sounds were normal apart from a soft mid- systolic murmur in the pulmonary area. There were no signs of cardiac failure.

Chest and abdomen were entirely normal.

In the central nervous system there were generalized choreiform movements of the hands and legs. The tongue demonstrated restless side-to-side and back-and-forth movements.

Examination of the endocrine system showed smooth, firm enlargement of both lobes of the thyroid with a marked bruit.

The investigations of interest were an initially raised inorganic phosphate at $6 \mathrm{mg} / 100 \mathrm{ml}$ ando̊ serum calcium at $12 \mathrm{mg} / 100 \mathrm{ml}$ with alkaline phosphatase at 250 i.u./l. The ${ }^{131}$ I uptake was $84 \%$ o of initial dose within $24 \mathrm{hr}$-(normal range 30-60\% in $24 \mathrm{hr}$ ). Serum protein bound iodine was 14.9 $\mathrm{mg} / 100 \mathrm{ml}$. Serum magnesium was $0.39 \mathrm{mmol} / \mathrm{l}$ (normal range, $0 \cdot 7-1.0 \mathrm{mmol} / \mathrm{l}$ ).

She was treated with carbimazole $15 \mathrm{mg}$ thrice daily, diazepam $4 \mathrm{mg}$ thrice daily, and amylobarbitone $100 \mathrm{mg}$ thrice daily.

One year later when she was euthyroid she underwent the operation of sub-total thyroidectomy. Microscopically this showed a diffusely toxic goitre.

Nine years' follow-up have revealed no new signs or symptoms of either thyrotoxicosis or choreoathetosis.

\section{Patient 2}

A 44-year-old married woman with 2 children worked as a part-time assistant in a store. For the 6 months before presentation she was aware of tremor, agitation and hyperhidrosis. The tremor made it impossible for her to carry out her household duties or manage her job because her movements were so jerky and unpredictable. She would also drop things frequently. She was referred to hospital.

Examination on admission showed a restless, continually moving patient who obviously suffered from hyperhidrosis. No abnormality was discovered in the cardiovascular system save for a pulse rate of $110 / \mathrm{min}$. The respiratory system and abdomen 
were entirely normal. In the musculo-skeletal system there was a severe myopathy particularly of the proximal muscles. She had frequent choreiform movements of the fingers and toes and unpredictable movements of the neck. There was an interrupted respiratory pattern, and gesticulation with both arms. In addition there was choreic tongue protrusion. The reflexes were brisk.

Examination of the thyroid gland revealed a smooth gland with a bruit and no nodularity. Serum thyroxine was $261 \mathrm{nmol} / 1$. Serum magnesium was 0.51 and serum alkaline phosphatase 154 i.u./l. There was no evidence of thyroid bone disease.

She was put on carbimazole $15 \mathrm{mg}$ thrice daily with ubvious improvement, and within 4 weeks all choreiform movements had disappeared. Progress at follow-up has remained satisfactory. She has remained euthyroid and free from abnormal movements. The patient has undergone recent partial thyroidectomy with good results.

\section{Discussion}

These are 2 cases that show chorea and choreoathetosis. The fact that the chorea responded to carbimazole treatment and did not recur, strongly implies that it was caused by the thyrotoxicosis and excessive secretion of thyroid hormones. It is suggested that the tremor of mild thyrotoxicosis is one end of a spectrum and choreo-athetosis represents the most severe form of inco-ordination. In cases of chorea described (Heffron and Eaton,
1970) the cessation of choreiform movement corresponded temporarily with the administration of antithyroid drugs and the resolution of the thyrotoxicosis. Treatment with propranolol produces resolution of the chorea within a matter of hours with no associated change in PBI or serum thyroxine. This observation suggests that the chorea is mediated by the sympathetic nervous system. The relationship between the sympathetic nervous system and thyrotoxicosis has been of interest since the observation of Goetsch (1918) that epinephrine exaggerated many of the signs and symptoms of thyrotoxicosis.

However, it has been found consistently that the concentration of circulating catecholamines is physiologically augmented by a surfeit of thyroid hormone. For this reason treatment with sympatholytic agents has constituted one therapeutic approach to thyrotoxicosis resulting in the use of reserpine, guanethidine, and propranolol most recently. The first 2 drugs deplete body stores of catecholamines and the third actually blocks the receptor.

\section{References}

Hall, R., Anderson, J. \& SMART, G. (1969) Fundamentals of Clinical Endocrinology, p. 65. Pitman Medical, London.

HefFron, H. \& EATON, R.P. (1970) Thyrotoxicosis presenting as choreoathetosis. Annals of Internal Medicine, 73, 425.

GOETSCH, E. (1918) Newer methods in the diagnosis of thyroid disorders. New York Journal of Medicine, 18, 259.

Marks, P. \& Ashraf, H. (1978) Apathetic hyperthyroidism with hypomagnesaemia and mixed alkaline phosphatase concentration. British Medical Journal, 1, 831. 